\title{
DIVISION XII / COMMISSION 14 / WORKING GROUP COLLISION PROCESSES
}

\author{
CO-CHAIRS Gillian Peach \\ Milan S. Dimitrijevic
}

\section{TRIENNIAL REPORT 2009-2012}

\section{Introduction}

Research in atomic and molecular collision processes and spectral line broadening has been very active since our last report, Peach, Dimitrijević \& Stancil 2009. Given the large volume of the published literature and the limited space available, we have attempted to identify work most relevant to astrophysics. Since our report can not be comprehensive, additional publications can be found in the databases at the web addresses listed in the final section. Elastic and inelastic collisions among electrons, atoms, ions, and molecules are included and charge transfer can be very important in collisions between heavy particles.

Numerous meetings on collision processes and line broadening have been held throughout the report period. Important international meetings that provide additional sources of data through their proceedings are: the 19th International Conference on Spectral Line Shapes (ICSLS) (Gigosos \& González 2008), the $7^{\text {th }}$ Serbian Conference on Spectral Line Shapes in Astrophysics (SCSLSA) (Popović \& Dimitrijević 2009), the XXVI International Conference on Photonic, Electronic, and Atomic Collisions (ICPEAC) (Orel et al. 2009 ), the $20^{\text {th }}$ ICSLS (Lewis \& Predoi-Cross 2010), the $22^{\text {nd }}$ International Conference on Atomic Physics (ICAP) (Bachor, Drummond \& Hannaford 2011), and the $7^{\text {th }}$ International Conference on Atomic and Molecular Data and their Applications (Bernotas,

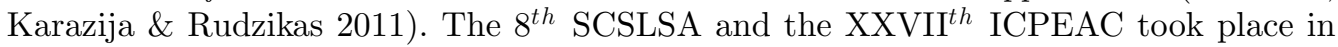
June and July 2011 and their proceedings will be published in Baltic Astronomy and Journal of Physics: Conference Series, respectively.

\section{Electron collisions with atoms and molecules}

Collisions of electrons with atoms, molecules and atomic and molecular ions are the major excitation mechanism for a wide range of astrophysical environments. In addition, electron collisions play an important role in ionization and recombination, contribute to cooling and heating of the gas, and may contribute to molecular fragmentation and formation. In the following sections we summarize recent work on collisions for astrophysically relevant species, including elastic scattering, excitation, ionization, dissociation, recombination and electron attachment and detachment.

A review has been published of the atomic data necessary for the non-LTE analysis of stellar spectra (Mashonkina 2009). Other references are listed below for scattering by the atoms and molecules specified.

\subsection{Electron scattering by neutral atoms}

Elastic scattering: H (screened Coulomb interactions) (Zhang et al. 2010), Mg (Zatsarinny et al. 2009), Ar (Gargioni \& Grosswendt 2008), I (Zatsarinny et al. 2011), Mn, Cu, Zn, 
Ni, Ag, Cd (Felfli et al. 2011), Rb, Cs, Fr (Gangwar et al. 2010).

Excitation: H (screened Coulomb interactions) (Zhang et al. 2010, Zhang et al. 2011), $\mathrm{He}\left(2^{1,3} \mathrm{~S}\right)$ (Wang et al. 2009, Wang et al. 2010), He, Ne (Kretinin et al. 2008), $\mathrm{Mg}$ (Zatsarinny et al. 2009), Ar (Gargioni \& Grosswendt 2008).

Ionization: He (Bray et al. 2010, Ren et al. 2011), $\mathrm{He}\left(2^{1} \mathrm{~S}\right)$ (Wang et al. 2010), Ar (Gargioni \& Grosswendt 2008).

Total cross section: Na (Jiao et al. 2010).

\subsection{Electron scattering by atomic ions}

Elastic scattering: $\mathrm{Mg}^{+}, \mathrm{Ca}^{+}$(Mitroy \& Zhang 2008).

Excitation: Hydrogen isoelectronic sequence $\mathrm{Cr}^{23+}-\mathrm{Ni}^{27+}$ (Malespin et al. 2011), Lithium isoelectronic sequence $\mathrm{Be}^{+}-\mathrm{Kr}^{33+}$ (Liang \& Badnell 2011), $\mathrm{Ne}^{3+}, \mathrm{Ne}^{6+}$ (Ludlow et al . 2011), Neon isoelectronic sequence $\mathrm{Na}^{+}-\mathrm{Kr}^{26+}$ (Liang \& Badnell 2010), Sodium isoelectronic sequence $\mathrm{Mg}^{+}-\mathrm{Kr}^{25+}$ (Liang et al. 2009b), $\mathrm{Mg}^{4+}$ (Hudson et al. 2009), $\mathrm{Mg}^{8+}$ (Del Zanna et al. 2008), $\mathrm{Si}^{9+}$ (Liang et al. 2009a), $\mathrm{S}^{8+}-\mathrm{S}^{1+}$ (Liang et al. 2011), $\mathrm{K}^{+}$(Tayal \& Zatsarinny 2010), $\mathrm{Fe}^{10+}$ (Del Zanna et al. 2010), Fe ${ }^{12+}$ (Storey \& Zeippen 2010), $\mathrm{Fe}^{18+}$ (Butler \& Badnell 2008), $\mathrm{Ni}^{10+}$ (Aggarwal \& Keenan 2008a), $\mathrm{Ni}^{18+}$ (Aggarwal \& Keenan 2008c).

Recombination: $\mathrm{H}^{+}$(Chluba et al. 2010), $\mathrm{N}^{+}$(Fang et al. 2011), Aluminium isoelectronic sequence $\mathrm{Si}^{+}-\mathrm{Zn}^{17+}$ (Abdel-Naby et al. 2011), Argon isoelectronic sequence $\mathrm{K}^{+}-\mathrm{Zn}^{12+}$ (Nikolić et al. 2010), $\mathrm{Fe}^{7}+, \mathrm{Fe}^{8+}$ (Schmidt et al. 2008), Selenium ions $\mathrm{Se}^{q+}, q=1-6$ (Sterling \& Witthoeft 2011).

Energy levels, radiative and excitation rates: $\mathrm{O}^{3+}$ (Aggarwal \& Keenan 2008b, Keenan et al. 2009), $\mathrm{O}^{6+}$ (Aggarwal \& Keenan 2008d), $\mathrm{Si}^{+}$(Bautista et al. 2009), $\mathrm{Ar}^{17+}$ (Aggarwal et al. 2008), Selenium ions $\mathrm{Se}^{q+}, q=1-6$ (Sterling \& Witthoeft 2011).

X-ray line emission: $\mathrm{Na}^{9+}$ (Phillips et al. 2010).

Radiative and Auger decay: Aluminium ions $\mathrm{Al}^{q+}, q=0-11$ (Palmeri et al. 2011).

\subsection{Electron scattering by molecules}

Elastic scattering: $\mathrm{H}_{2} \mathrm{O}$ (Liu \& Zhou 2010), $\left(\mathrm{H}_{2} \mathrm{O}\right)_{2}$ (Bouchiha et al. 2008), $\mathrm{Li}_{2}$ (Tarana \& Tennyson 2008), CO (Allan 2010), NH (Rajvanshi \& Baluja 2010), $\mathrm{NO}_{2}$ (Munjal et al. 2009), $\mathrm{S}_{2}$ (Rajvanshi \& Baluja 2011), $\mathrm{SO}_{2}$ (Machado et al. 2011), SOS (Kaur et al. 2010), $\mathrm{S}_{3}$ (Kaur et al. 2011).

Electron exchange: $\mathrm{O}_{2}, \mathrm{NO}, \mathrm{NO}_{2}$ (Holtkötter \& Hanne 2009).

Excitation: $\mathrm{H}_{2}$ (Kretinin et al. 2008), $\mathrm{Li}_{2}$ (Tarana \& Tennyson 2008), CO (Allan 2010), $\mathrm{N}_{2}$ (Kato et al. 2010, Johnson et al. 2010, Mavadat et al. 2011), NH (Rajvanshi \& Baluja 2010), $\mathrm{NO}_{2}$ (Munjal et al. 2009), $\mathrm{S}_{2}$ (Rajvanshi \& Baluja 2011), SOS (Kaur et al. 2010), $\mathrm{S}_{3}$ (Kaur et al. 2011), $\mathrm{C}_{2} \mathrm{H}_{4}$ (da Costa et al. 2008).

Ionization: $\mathrm{N}_{2}$ (Gochitashvili et al. 2010), NH (Rajvanshi \& Baluja 2010), SiCl, $\mathrm{SiCl}_{2}$, $\mathrm{SiCl}_{3}, \mathrm{SiCl}_{4}$ (Kothari et al. 2011), SO, $\mathrm{SO}_{2}$ (Vinodkumar et al. 2008), SOS (Kaur et al. 2010), $\mathrm{S}_{2}$ (Rajvanshi \& Baluja 2011), $\mathrm{S}_{3}$ (Kaur et al. 2011).

Total cross sections: $\mathrm{SO}, \mathrm{SO}_{2}, \mathrm{SO}_{2} \mathrm{Cl}_{2}, \mathrm{SO}_{2} \mathrm{ClF}, \mathrm{SO}_{2} \mathrm{~F}_{2}$ (Joshipura \& Gangopadhyay 2008), $\mathrm{SO}_{2}$ (Machado et al. 2011), $\mathrm{C}_{2} \mathrm{H}_{4} \mathrm{O}$ (Szmytkowski et al. 2008), $\mathrm{CH}_{3} \mathrm{OH}, \mathrm{CH}_{3} \mathrm{NH}_{2}$ (Vinodkumar et al. 2008).

Dissociative processes: $\mathrm{H}_{2}$ (Celiberto et al. 2009, Bellm et al. 2010, Celiberto et al. 2011), $\mathrm{HCl}$ (Fedor et al. 2010), $\mathrm{HCl}, \mathrm{DCl}, \mathrm{HBr}, \mathrm{DBr}$ (Fedor et al. 2008), $\mathrm{C}_{2} \mathrm{H}_{2}$ (Chourou \& Orel 2008). 
Attachment: $\mathrm{C}_{2} \mathrm{H}, \mathrm{C}_{2} \mathrm{~N}$ (Harrison \& Tennyson 2011).

\subsection{Electron scattering by molecular ions}

Detachment: $\mathrm{C}_{2}^{-}$(Halmová et al. 2008).

Excitation: $\mathrm{C}_{2}^{-}$(Halmová et al. 2008), $\mathrm{CO}^{+}$(Stäuber \& Bruderer 2009).

Rotational cooling: $\mathrm{HD}^{+}$(Shafir et al. 2009).

Dissociative and recombination processes: $\mathrm{HD}^{+}$(Fifirig \& Stroe 2008, Takagi et al. 2009, Stroe \& Fifirig 2011), $\mathrm{H}_{3}^{+}$(Glosík et al. 2009), $\mathrm{HF}^{+}$(Roos et al. 2008, Roos et al. 2009), $\mathrm{CH}_{3}^{+}, \mathrm{CD}_{3}^{+}$(Bahati et al. 2009), $\mathrm{CD}_{3} \mathrm{OCD}_{2}^{+},\left(\mathrm{CD}_{3}\right)_{2} \mathrm{OD}^{+}$(Hamberg et al. 2010a), $\mathrm{CD}_{3} \mathrm{CDOD}^{+}, \mathrm{CH}_{3} \mathrm{CH}_{2} \mathrm{OH}_{2}^{+}$(Hamberg et al. 2010b).

\section{Collisions between heavy particles}

A review entitled 'Energetic ion, atom and molecule reactions and excitation in $\mathrm{H}_{2}$ discharges' has recently been published (Phelps 2009). Other references are listed below for the atomic and molecular processes specified.

\subsection{Collisions between neutral atoms and atomic ions}

Inelastic scattering: $\mathrm{H}+\mathrm{H}$ (Barklem et al. 2011), $\mathrm{Na}+\mathrm{H}$ (Barklem et al. 2010).

Excitation: $\mathrm{H}+\mathrm{H}^{+}$(Winter 2009).

Charge transfer processes: H, D, T $+\mathrm{He}^{2+}$ (Stolterfoht et al. 2010), $\mathrm{H}^{-}+\mathrm{H}^{+}$, mutual neutralization (Stenrup et al. 2009), $\mathrm{H}+\mathrm{H}^{+}$(Winter 2009), $\mathrm{H}+\mathrm{Li}^{2+}$ (Mančev 2009), $\mathrm{H}+\mathrm{B}^{5+}, \mathrm{C}^{4+}$ (Barragán et al. 2010), $\mathrm{H}+\mathrm{C}^{3+}, \mathrm{O}^{3+}, \mathrm{Si}^{3+}$ (Guevara et al. 2011), $\mathrm{H}^{+}+$ $\mathrm{Li}^{+}, \mathrm{Be}^{2+}, \mathrm{B}^{3+}, \mathrm{C}^{4+}$ (Samanta \& Purkait 2011), He $+\mathrm{H}^{+}$(Guzmán et al. 2009, Harris et al. 2010, Fischer et al. 2010), $\mathrm{He}+\mathrm{H}^{+}, \mathrm{He}^{2+}$ (Zapukhlyak \& Kirchner 2009), $\mathrm{He}+$ $\mathrm{H}^{+}, \mathrm{He}^{+}, \mathrm{He}^{2+}$ (Schöffler et al. 2009), $\mathrm{He}+{ }^{3} \mathrm{He}^{2+}$ (Alessi et al. 2011), $\mathrm{He}+\mathrm{He}^{2+}, \mathrm{Li}^{+}$, $\mathrm{Li}^{2+}, \mathrm{Li}^{3+}, \mathrm{C}^{6+}, \mathrm{O}^{8+}$ (Samanta et al. 2011), $\mathrm{He}+\mathrm{C}^{3+}$ (Wu et al. $\left.2009 \mathrm{~b}\right), \mathrm{He}+\mathrm{N}^{3+}$ (Liu et al. 2011b), $\mathrm{He}+\mathrm{O}^{3+}$ (Kamber et al. 2008, Wu et al. 2009a), He, Ne, Ar, Kr, Xe $+\mathrm{C}^{3+}$ (Santos et al. 2010), $\mathrm{He}^{+}+\mathrm{He}^{+}$(Mančev 2009),

$\mathrm{Li}+\mathrm{H}, \mathrm{H}^{+}$(Cabrera-Trujillo et al. 2008), $\mathrm{Li}+\mathrm{H}^{+}$(Liu et al. 2011a), $\mathrm{Ne}+\mathrm{C}^{2+}, \mathrm{C}^{3+}$, $\mathrm{O}^{2+}, \mathrm{O}^{3+}$ (Ding et al. 2008), $\mathrm{Na}+\mathrm{H}$ ion-pair production (Barklem et al. 2010), $\mathrm{Mg}+$ $\mathrm{H}^{+}, \mathrm{He}^{2+}$ (Kumari et al. 2011), $\mathrm{Mg}+\mathrm{Cs}^{+}$(Sabido et al. 2008), $\mathrm{Ar}+\mathrm{H}^{+}$(CabreraTrujillo et al. 2009), $\mathrm{Ar}+\mathrm{O}^{3+}$ (Kamber et al. 2008).

Ionization: $\mathrm{H}+\mathrm{H}^{+}$(Winter 2009), $\mathrm{He}+\mathrm{H}^{+}$(Guzmán et al. 2009), $\mathrm{He}+\mathrm{He}^{2+}$ (Ogurtsov et al. 2011), He, Ne, Ar, Kr, Xe $+\mathrm{H}^{+}$(Miraglia \& Gravielle 2008), He, Ne, Ar, Kr, Xe $+\mathrm{C}^{3+}$ (Santos et al. 2010), $\mathrm{Li}^{+}, \mathrm{Na}^{+}, \mathrm{K}^{+}, \mathrm{Rb}^{+}+\mathrm{H}^{+}$(Miraglia \& Gravielle 2008).

Detachment: $\mathrm{C}^{-}, \mathrm{O}^{-}, \mathrm{F}^{-}, \mathrm{Na}^{-}, \mathrm{Si}^{-}, \mathrm{S}^{-}, \mathrm{Cl}^{-}, \mathrm{Ge}^{-}+\mathrm{He}, \mathrm{Ne}$, Ar (Jalbert et al. 2008), $\mathrm{F}^{-}, \mathrm{Cl}^{-}, \mathrm{Br}^{-}, \mathrm{I}^{-}+\mathrm{H}^{+}$(Miraglia \& Gravielle 2008).

Energy loss and stopping cross sections: $\mathrm{Li}+\mathrm{H}, \mathrm{H}^{+}$(Cabrera-Trujillo et al. 2008), H, $\mathrm{D}, \mathrm{T}+\mathrm{He}^{2+}$ (Cabrera-Trujillo et al. 2011).

\subsection{Collisions between atoms and molecules}

Dissociative processes: $\mathrm{H}_{2} \mathrm{O}+\mathrm{H}^{+}$(Monce et al. 2009), $\mathrm{H}_{2} \mathrm{O}+\mathrm{He}^{+}$(Garcia et al. 2008). Radiative association: $\mathrm{H}_{2}+\mathrm{H}^{-}$(Ayouz et al. 2011).

Excitation and/or fragmentation: $\mathrm{CN}^{-}+\mathrm{H}_{2}$ (Agúndez et al. 2010), $\mathrm{CO}^{+}+\mathrm{H}$ (Andersson et al. 2008), $\mathrm{CO}_{2}^{+}+\mathrm{He}$ (González-Magaña et al. 2008), $\mathrm{CO}^{+}+\mathrm{H}, \mathrm{H}_{2}$ (Stäuber \& Bruderer 2009). 
Charge transfer processes: $\mathrm{D}_{2}, \mathrm{O}_{2}, \mathrm{H}_{2} \mathrm{O}, \mathrm{CO}_{2}+\mathrm{O}^{3+}$ (Kamber et al. 2008), $\mathrm{H}_{2}+\mathrm{He}^{2+}$ (Khoma et al. 2009), $\mathrm{CH}_{3}+\mathrm{H}^{+}$(Nagao et al. 2008), $\mathrm{CO}_{2}+\mathrm{He}^{+}$(Lin \& Mayer 2010), $\mathrm{HCl}+\mathrm{C}^{2+}$ (Rozsályi et al. 2011).

Ionization and/or capture: $\mathrm{H}_{2} \mathrm{O}+\mathrm{H}^{+}, \mathrm{He}^{2+}, \mathrm{C}^{6+}$ (Illescas et al. 2011), $\mathrm{C}_{2} \mathrm{H}_{4}+\mathrm{H}^{+}$ (Getahun et al. 2010), $\mathrm{N}_{2}+\mathrm{H}^{+}$(Gochitashvili et al. 2010).

\section{Stark broadening}

Knowledge of Stark broadening parameters (line widths and shifts) for a large number of atomic transitions is very important for the analysis, interpretation and modelling of stellar spectra, circumstellar conditions and H II regions. For hot dense stars such as white dwarfs this is often the most important broadening mechanism.

\subsection{Developments in line broadening theory}

Rosato et al. (2009) have reexamined the Stark broadening of hydrogen lines in the presence of a magnetic field and developed an impact theory for ions, valid for low electron densities $\left(N_{e} \leqslant 10^{14} \mathrm{~cm}^{-3}\right)$, which takes into account the Zeeman splitting of the atomic energy levels. Rosato et al. (2010) have also studied numerically the role of time ordering in such plasmas, by using a simulation code that accounts for the evolution of the microscopic electric field generated by the charged particles moving close to the atom. Calisti et al. (2010) have developed a very fast method to account for the dynamical effects of charged particles on the spectral line shape emitted by plasmas, based on a formulation of the frequency fluctuation model.

$A b$ initio calculations of Stark broadening parameters, i.e. calculations where the required atomic energy levels and oscillator strengths are determined during the calculation and are not taken from other sources, have been considered and reviewed by Ben Nessib (2009). A book has recently been published (Gordon \& Sorochenko 2009) that gives a detailed account of the surprising discovery in the 1960's of the radio recombination lines and their subsequent analysis. Even now some features have still not been satisfactorily explained.

\subsection{Isolated lines}

For isolated lines Stark broadening is dominated by collisions with plasma electrons. Broadening parameters have been determined theoretically for:

One line from the 3s-3p transition array for each of the spectra Si XI, Ti XI, Cr XIII, Cr XIV, Fe XV, Fe XVI, Ni XVIII and Fe XXIII and two lines from the array for K VIII, Ca IX, Sc X and Ti XI (Elabidi \& Sahal-Bréchot 2011); two lines for 3s-3p transitions for ions C IV, N V, O VI, F VII, Na IX, Mg X, Al XI, Si XII and P XIII and one line for Ne VIII (Elabidi et al. 2009); the 2s-2p resonance doublets of C IV, N V, O VI, F VII and Ne VIII ions (Elabidi et al. 2011). These calculations all use a quantum mechanical approach.

For five lines of $\mathrm{Cu}$ I (Zmerli et al. 2010) and the lines Ne I $837.8 \mathrm{~nm}$ (Christova et al. 2010b) and Ar I $737.2 \mathrm{~nm}$ (Christova et al. 2010a), new Stark broadening parameters are obtained using a semiclassical perturbation approach. A semi-empirical approach, which uses a set of wave functions obtained from Hartree-Fock relativistic calculations and includes core polarization effects, has been applied to 58 lines of $\mathrm{Pb}$ IV (Alonso-Medina et al. 2010) and 171 lines of Sn III (Alonso-Medina \& Colón 2011).

Broadening parameters have been obtained experimentally for the following numbers of lines: 
$34 \mathrm{~Pb}$ I (Alonso-Medina 2008), $25 \mathrm{~Pb}$ III (Alonso-Medina 2011), $34 \mathrm{~Pb}$ IV and $4 \mathrm{~Pb} \mathrm{~V}$ (Bukvić et al. 2011), 28 Cd III (Djeniže et al. 2009, Bukvić et al. 2009b), 13 Si I, 15 Si II, 28 Si III and 9 Si IV (Bukvić et al. 2009a), 29 (Bukvić et al. 2008) and 19 (Djurović et al. 2011) Ar III, 30 Kr III (Ćirišan et al. 2011), 12 Ne II, 8 Kr II and 5 Xe II (Peláez et al. 2010b), 38 Xe II (Peláez et al. 2009a, Peláez et al. 2009b), 10 Xe III (Peláez et al. 2009b), $5 \mathrm{Au} \mathrm{I}$ and $26 \mathrm{Au}$ II (Djeniže 2009), 9 Sb III (Djeniže 2008), $15 \mathrm{Mn} \mathrm{I}$ and 10 Fe I (Zielinska et al. 2010), 21 Fe II (Aragón et al. 2011) and C I 833.5 nm (Bartecka et al. 2011).

The regularities and systematic trends of Stark broadening parameters and reasons for deviations have been investigated within the multiplets (Peláez et al. 2010b, Peláez et al. 2009a), along the homologous sequence of singly-ionized noble gases (Peláez et al. 2010a), within the spectral series (Christova et al. 2010a) and along isoelectronic sequences (Elabidi et al. 2009, Elabidi et al. 2011). Also the dependence of electron- and proton-impact Stark widths on the upper-level ionization potential within different series of spectral lines of neutral magnesium (Tapalaga et al. 2011) and as a function of charge on the atomic core (Elabidi \& Sahal-Bréchot 2011) have been evaluated and discussed. This kind of trend and regularity analysis can be useful for the prediction of Stark broadening parameters and therefore for the spectroscopic diagnostic of astrophysical plasmas.

\subsection{Transitions in hydrogenic and helium-like systems}

Stark-broadened line profiles of the hydrogen Brackett series have been computed within the Model Microfield Method for the conditions of stellar atmospheres and circumstellar envelopes (Stéhle \& Fouquet 2010), and Tremblay \& Bergeron (2009) have performed improved calculations for the Stark broadening of hydrogen lines in dense plasmas typical of white-dwarf atmospheres. The central asymmetry of the $\mathrm{H} \beta$ line has been measured and analysed (Djurović et al. 2009) and new experimental results for $\mathrm{H} \alpha$ and $\mathrm{H} \gamma$ have been published (Mijatović et al. 2010a, Mijatović et al. 2010b).

Omar $(2010,2011)$ published new calculations for the Stark broadening of the He I lines at $504.8 \mathrm{~nm}, 388.9 \mathrm{~nm}, 318.8 \mathrm{~nm}, 667.8 \mathrm{~nm}$ and $501.6 \mathrm{~nm}$ formed in a dense plasma. Tables of Stark broadening for the He I $447.1 \mathrm{~nm}$ line have been generated using computer simulations (Gigosos \& González 2009). This line and its forbidden component have also been studied theoretically (González et al. 2011) and experimentally (Ivković et al. 2010, González et al. 2011). Gao et al. (2008) have carried out experiments for the He I $388.9 \mathrm{~nm}$ and $706.5 \mathrm{~nm}$ lines.

\section{Broadening by neutral atoms and molecules}

The analysis of experimental molecular spectra in order to extract line shape parameters is often very difficult. Line shapes can be affected by collisional narrowing and the dependence of collisional broadening and shifting on molecular speed. When these effects are sufficiently important, fitting Voigt profiles to experimental spectra produces systematic errors in the parameters retrieved. Here the experimental and theoretical results selected have been confined to the basic atomic and molecular data required for a description of the pressure broadening and shift of lines and molecular bands.

Since the last report an important book has been published (Hartman et al. 2008) that gives a comprehensive review of experimental and theoretical work on collisional effects in molecular spectra. In the following sections the items are labelled by ' $\mathrm{E}$ ' and ' $\mathrm{T}$ ' to indicate experimental work and theoretical analysis, respectively. 


\subsection{Broadening and shift of atomic lines}

New research has been published in the period 2008-2011 and the transitions studied together with the perturbing atoms or molecules are listed below. The work is theoretical except where indicated by 'E'.

$\mathrm{H}$ : line wings of Ly $\alpha$ broadened by $\mathrm{H}$ and He (Allard et al. 2009a, Allard \& Christova 2009); line wings of $\mathrm{Ly} \gamma$ by $\mathrm{H}^{+}$(Allard et al. 2009b) and $\mathrm{H} \alpha$ by $\mathrm{H}$ (Allard et al. 2008). He: self broadening of line $3 \mathrm{~s}^{3} \mathrm{~S}-2 \mathrm{p}^{3} \mathrm{P}$ (Allard et al. 2009c, Allard et al. 2011).

Li: self broadening of resonance line (Reggami et al. 2009); resonance line broadened by He (Peach \& Whittingham 2009, Peach 2010a, Peach 2010b); 2s-3d transition broadened by Ne and Ar (Rosenberry \& Stewart 2011).

Na: resonance line broadened by H (Peach 2010b); lines 3s-3p and 3p-3d broadened by He (Peach \& Whittingham 2009, Peach 2010a, Peach 2010b).

$\mathrm{K}$ : self broadening of resonance line (Reggami et al. 2009) and line wings (Talbi et al. 2008).

$\mathrm{K}, \mathrm{Rb}$ and Cs: self broadening of principal series (E) (Vadla et al. 2009).

Rb: 5s-5p D2 line, broadening by $\mathrm{He}, \mathrm{CH}_{4}, \mathrm{C}_{2} \mathrm{H}_{6}, \mathrm{C}_{3} \mathrm{H}_{8}, \mathrm{n}-\mathrm{C}_{4} \mathrm{H}_{10}$ (E) (Zameroski et al. 2011).

Cs: 6s-6p D2 line, broadening by ${ }^{3} \mathrm{He}, \mathrm{H}_{2}, \mathrm{HD}, \mathrm{D}_{2}, \mathrm{~N}_{2}, \mathrm{CH}_{4}, \mathrm{C}_{2} \mathrm{H}_{6}, \mathrm{CF}_{4}$ (E) (Pitz et al. 2010).

\subsection{Broadening and shift of molecular lines}

Much new data have been published since the last report was prepared. The molecules are listed below with their perturbing atomic or molecular species and are labelled by ' $\mathrm{E}$ ' and ' $\mathrm{T}$ ' to indicate experimental work and theoretical analysis, respectively.

$\mathrm{H}_{2}$-Ar: collision-induced absorption (T) (Tran et al. 2011b).

$\mathrm{D}_{2}-\mathrm{Kr}$ : collision-induced absorption (E) (Abu-Kharma et al. 2010).

HI: lines broadened by $\mathrm{N}_{2}$ (E) (Domanskaya et al. 2011).

HBr: self broadening (E) (Domanskaya et al. 2009).

$\mathrm{HI}$ and HBr: lines broadened by rare gases (E) (Domanskaya et al. 2009).

HDO: lines broadened by $\mathrm{CO}_{2}$ (T) (Gamache et al. 2011).

$\mathrm{HCl}$ : lines broadened and shifted by $\mathrm{N}_{2}, \mathrm{He}$, Ar and Xe (E) (Hurtmans et al. 2009).

$\mathrm{HCN}$ : lines broadened by $\mathrm{N}_{2}, \mathrm{O}_{2}$ and air (E) (Yang et al. 2008).

$\mathrm{H}_{2} \mathrm{CO}$ : lines broadened by $\mathrm{H}_{2} \mathrm{CO}$ and $\mathrm{N}_{2}$ (E+T) (Jacquemart et al. 2010).

$\mathrm{HNO}_{3}$ : lines broadened by $\mathrm{N}_{2}$ (T) (Laraia et al. 2009).

$\mathrm{HO}_{2}$ : lines broadened by $\mathrm{N}_{2}$ (E) (Miyano \& Tonokura 2011).

$\mathrm{H}_{2} \mathrm{O}_{2}$ : lines broadened by $\mathrm{N}_{2}, \mathrm{O}_{2}$ and air (E) (Sato et al. 2010).

$\mathrm{H}_{2} \mathrm{O}$ : lines broadened by $\mathrm{H}_{2}$ (E) (Krupnov 2010), (T) (Wiesenfeld \& Faure 2010); by $\mathrm{H}_{2}$ and $\mathrm{He}$ (E) (Dick et al. 2010); by $\mathrm{N}_{2}$ (E) (Lavrentieva et al. 2010; by $\mathrm{N}_{2}$ and $\mathrm{O}_{2}$ (T) (Gamache \& Laraia 2009); by $\mathrm{O}_{2}$ (E) (Petrova et al. 2011; by $\mathrm{H}_{2} \mathrm{O}$ (E) (Lisak et al. 2009, Ptashnik \& Smith 2010); by $\mathrm{H}_{2} \mathrm{O}, \mathrm{N}_{2}, \mathrm{O}_{2}$ (E+T) (Cazzoli et al. 2008, Cazzoli et al. 2009, Koshelev 2011); by air (T) (Voronin et al. 2010); by $\mathrm{CO}_{2}$ (T) (Sagawa et al. 2009); by $\mathrm{H}_{2}, \mathrm{He}, \mathrm{N}_{2}, \mathrm{O}_{2}$ and $\mathrm{CO}_{2}$ (E) (Dick et al. 2009b); by rare gases (E+T) (Fiadzomor et al. 2008).

$\mathrm{CH}_{4}$ : lines broadened by $\mathrm{N}_{2}$ (T) (Gabard \& Boudon 2010); by $\mathrm{N}_{2}$ and $\mathrm{O}_{2}$ (E) (Lyulin et al. 2009); by $\mathrm{CH}_{4}$ (E) (Smith et al. 2010, Lyulin et al. 2011); by $\mathrm{CH}_{4}$ and $\mathrm{N}_{2}$ (E) (McRaven et al. 2011); by $\mathrm{O}_{2}$ and air (E) (Martin \& Lepère 2009); by air (E) (Smith et al. 2009, Smith et al. 2011).

$\mathrm{C}_{2} \mathrm{H}_{2}$ : broadened by $\mathrm{H}_{2}$ (T) (Thibault et al. 2011a); by $\mathrm{H}_{2}$ and $\mathrm{D}_{2}(\mathrm{E}+\mathrm{T}$ ) (Thibault 
et al. 2009); by $\mathrm{N}_{2}$ (E) (Dhyne et al. 2009, Fissiaux et al. 2009, Dhyne et al. 2010); by $\mathrm{C}_{2} \mathrm{H}_{2}$ (E) (Li et al. 2010, Povey et al. 2011, Dhyne et al. 2011); by He and Ar (T) (Ivanov \& Buzykin 2010); by Ne and Kr (E) (Nguyen et al. 2009a).

$\mathrm{C}_{2} \mathrm{H}_{4}$ : lines broadened by $\mathrm{C}_{2} \mathrm{H}_{4}$ (E) (Flaud et al. 2011); by $\operatorname{Ar}(\mathrm{E}+\mathrm{T})$ (Nguyen et al. 2009b).

$\mathrm{C}_{2} \mathrm{H}_{6}$ : lines broadened by $\mathrm{N}_{2}$ (E) (Blanquet et al. 2009); by $\mathrm{C}_{2} \mathrm{H}_{6}$ and $\mathrm{N}_{2}$ (E) (Devi et al. 2010b, Devi et al. 2010c); by $\mathrm{O}_{2}$ and air (E) (Fissiaux et al. 2010).

$\mathrm{CH}_{3} \mathrm{Br}$ : lines broadened by $\mathrm{N}_{2}$ (T) (Boussetta et al. 2011); by $\mathrm{CH}_{3} \mathrm{Br}, \mathrm{N}_{2}$ and $\mathrm{O}_{2}(\mathrm{E})$ (Hoffman \& Davies 2009); by $\mathrm{CH}_{3} \mathrm{Br}$ (T) (Goméz et al. 2010).

$\mathrm{CH}_{3} \mathrm{~F}$ : lines broadened by $\mathrm{CH}_{3} \mathrm{~F}$ and $\mathrm{He}(\mathrm{E})$ (Koubek et al. 2011).

CO: lines broadened by CO, $\mathrm{N}_{2}$ and $\mathrm{O}_{2}$ (E) (Koshelev \& Markov 2009); by $\mathrm{H}_{2}, \mathrm{~N}_{2}, \mathrm{O}_{2}$, $\mathrm{CO}, \mathrm{CO}_{2}$ and $\mathrm{He}$ (E) (Dick et al. 2009a).

$\mathrm{CO}_{2}$ : by $\mathrm{O}_{2}$ (E) (Devi et al. 2010a); by $\mathrm{CO}_{2}(\mathrm{E}+\mathrm{T}$ ) (Predoi-Cross et al. 2010, Tran et al. 2011a); by $\mathrm{CO}_{2}, \mathrm{~N}_{2}$ and $\mathrm{O}_{2}$ (E) (Li et al. 2008); by air (T) (Hartmann 2009), (E) (Gulidova et al. 2010), (E+T) (Lamouroux et al. 2010); by He (E) (Deng et al. 2009); by air and $\operatorname{Ar}$ (E) (Farooq et al. 2010).

$\mathrm{Cs}_{2}$ : lines broadened by $\mathrm{Cs}_{2}$ (E) (Misago et al. 2009).

$\mathrm{N}_{2}$ : lines broadened by $\mathrm{H}_{2}$ (T) (Goméz et al. 2011); by $\mathrm{N}_{2}$ (E+T) (Thibault et al. 2011b). $\mathrm{NH}_{3}$ : lines broadened by $\mathrm{H}_{2}$ and $\mathrm{He}$ (E) (Hanley et al. 2009); by $\mathrm{He}$ (T) (Dhib 2010; by $\mathrm{NH}_{3}$ (E) (Aroui et al. 2009, Guinet et al. 2011); by $\mathrm{NH}_{3}$ and $\mathrm{O}_{2}$ (E+T) (Nouri et al. 2009).

$\mathrm{O}_{2}$ : lines broadened by $\mathrm{O}_{2}$ (E) (Lisak et al. 2010, Wójtewicz et al. 2011); by $\mathrm{O}_{2}$ and $\mathrm{OO}$ isotopologues (E) (Long et al. 2011); by $\mathrm{O}_{2}$ and air (E) (Long et al. 2010).

$\mathrm{O}_{2}-\mathrm{CO}_{2}$ : collision-induced absorption (E) (Vangvichith et al. 2009).

$\mathrm{O}_{3}$ : lines broadened by air (Drouin \& Gamache 2008); by $\mathrm{N}_{2}$ and air (E+T) (Tran et al. 2011c).

OH: lines broadened by $\mathrm{N}_{2}, \mathrm{H}_{2} \mathrm{O}$ and $\mathrm{Ar}$ (E) (Hwang et al. 2008).

OCS lines broadened by $\mathrm{N}_{2}, \mathrm{O}_{2}$ and OCS (E) (Koshelev \& Tretyakov 2009); by $\mathrm{N}_{2}$ and $\mathrm{O}_{2}$ (E) (Galalou et al. 2011).

$\mathrm{I}_{2}$ : lines broadened by Ar (E) (Phillips \& Perram 2008).

\section{Databases}

Some useful databases are:

Vienna Atomic Line Database (VALD) of atomic data for analysis of radiation from astrophysical objects, containing central wavelengths, energy levels, statistical weights, transition probabilities and line broadening parameters for all chemical elements of astronomical importance. It can be found at http://vald.astro.univie.ac.at/ (Kupka et al. 1999).

The database of Robert L. Kurucz comprises atomic line parameters, including line broadening. An update to this database is discussed by Kurucz 2011. (http://kurucz.harvard.edu)

CHIANTI database (Dere et al. 2009) contains a critically evaluated set of up-todate atomic data for the analysis of optically thin collisionally ionized astrophysical plasmas. It lists experimental and calculated wavelengths, radiative data and rates for electron and proton collisions, see websites http://sohowww.nascom.nasa.gov/solarsoft and http://www.damtp.cam.ac.uk/user/astro/chianti/.

CDMS - Cologne Database for Molecular Spectroscopy, see website http://www.ph1.uni-koeln.de/vorhersagen/, provides recommendations for spectroscopic 
transition frequencies and intensities for atoms and molecules of astronomical interest in the frequency range 0-10 THz, i.e. $0-340 \mathrm{~cm}^{-1}$ (Müller et al. 2005).

BASECOL database (http://basecol.obspm.fr) contains excitation rate coefficients for ro-vibrational excitation of molecules by electrons, $\mathrm{He}$ and $\mathrm{H}_{2}$ and it is mainly used for the study of interstellar, circumstellar and cometary atmospheres.

TIPTOPbase (http://cdsweb.u-strasbg.fr/topbase/home.html) contains:

(i) TOPbase, that lists atomic data computed in the Opacity Project; namely LS-coupling energy levels, gf-values and photoionization cross sections for light elements $(Z \leqslant 26)$ of astrophysical interest and

(ii) TIPbase that lists intermediate-coupling energy levels, transition probabilities and electron impact excitation cross sections and rates for astrophysical applications $(\mathrm{Z} \leqslant$ 28), computed by the IRON Project.

HITRAN - (HIgh-resolution TRANsmission molecular absorption database) is at http://www.cfa. harvard.edu/hitran/ (Rothman et al. 2009). It lists individual line parameters for molecules in the gas phase (microwave through to the UV), photoabsorption cross-sections for many molecules, and refractive indices of several atmospheric aerosols. A high temperature extension to HITRAN is HITEMP (To access the HITEMP data: $\mathrm{ftp}$ to cfa-ftp.harvard.edu; user $=$ anonymous; password $=$ e-mail address). It contains data for water, $\mathrm{CO}_{2}, \mathrm{CO}, \mathrm{NO}$ and $\mathrm{OH}$ (Rothman et al. 2010).

GEISA - (Gestion et Etude des Informations Spectroscopiques Atmosphériques) is a computer-accessible spectroscopic database, designed to facilitate accurate forward radiative transfer calculations using a line-by-line and layer-by-layer approach. It can be found at http://ether.ipsl.jussieu.fr/etherTypo/?id=950 (Jacquinet-Husson et al. 2008).

NIST - The National Institute of Standards and Technology hosts a number of useful databases for Atomic and Molecular Physics. A list can be found at http://www.nist.gov/srd/atomic.cfm. Among them are: An atomic spectra database and three bibliographic databases providing references on atomic energy levels and spectra, transition probabilities and spectral line shapes and line broadening.

STARK-B database (http://stark-b.obspm.fr) contains theoretical widths and shifts of isolated lines of atoms and ions due to collisions with charged perturbers, obtained using the impact approximation (Sahal-Bréchot 2010).

The European FP7 project will finish at the end of 2012. The virtual Atomic and Molecular Data Centre (VAMDC - http://www.vamdc.eu/) is being created with the aim of building an accessible and interoperable e-infrastructure for atomic and molecular data that will upgrade and integrate European (and other) A\&M database services (Dubernet et al. 2011, Rixon et al. 2011).

\section{References}

Abdel-Naby, Sh. A., Nikolić, D., Gorczyca, T. W., et al. 2011, A\&AA, in press, DOI: http://dx.doi.org/10.1051/0004-6361/201117544

Abu-Kharma, M., Omari, H. Y., Shawaqfeh, N., \& Stamp, C. 2010, JMoSp, 259, 111

Aggarwal, K. M., Hamada, K., Igarashi, A., et al. 2008, A $\mathscr{E} A$, 487, 383

Aggarwal, K. M. \& Keenan, F. P. 2008a, EuPhJD, 46, 205

Aggarwal, K. M. \& Keenan, F. P. 2008b, A\&A, 486, 1053

Aggarwal, K. M. \& Keenan, F. P. 2008c, $A \& A$, 488, 365

Aggarwal, K. M. \& Keenan, F. P. 2008d, $A \& A$, 489, 1377

Agúndez, M., Cernicharo, J., Guélin, M., et al. 2010, A\&A, 517, L2

Alessi M., Otranto, S. \& Focke, P. 2011, PhRvA, 83, 014701

Allan, M. 2010, PhRvA, 81, 042706 
Allard, N. F., Kielkopf, J. F., Cayrel, R., \& Van’t Veer-memmerat, C. 2008, A\&\&A, 480, 581

Allard, N. F. \& Christova, M. 2009, New Astron. Rev., 53, 252

Allard, N. F. Kielkopf, J. F. 2009a, A\&3A, 493, 1155

Allard, N. F., Noselidze, I., \& Kruk, J. W. 2009b, A\&ऽA, 506, 993

Allard, N. F., Deguilhem, B., Gadea, F. X., et al. 2009c, EPL, 88, 53002

Allard, N. F., Bonifaci, N., \& Denat, A. 2011, EuPhJD, 61, 365

Alonso-Medina, A. 2008, Spectrochim. Acta B, 63, 598

Alonso-Medina, A., Colón, C., Montero, J. L., \& Nation, L. 2010, MNRAS, 401, 1080

Alonso-Medina, A. 2011, Spectrochim. Acta B, 66, 439

Alonso-Medina, A. \& Colón, C. 2011, MNRAS, 414, 713

Andersson, S., Barinovs, G.., \& Nyman, G. 2008, ApJ, 678, 1042

Aragón, C., Vega, P., \& Aguilera, J. A. 2011, JPhB: At. Mol. Opt. Phys., 44, 055002

Aroui, H., Laribi, H., Orphai, J., \& Chelin, P. 2009, JQSRT, 110, 2037

Ayouz, M., Lopes, R., Raoult, M., et al. 2011, PhRvA, 83, 052712

Bachor, H., Drummond, P., \& Hannaford, P., eds. 2011, Proc. $22^{\text {nd }}$ International Conference on Atomic Physics, JP-CS, 264

Bahati, E. M., Fogle, M., Vane, C. R., et al. 2009, PhRvA, 79, 052703

Barklem, P. S., Belyaev, A. K., Dickinson, A. S., \& Gadéa, F. X. 2010, A\&\&A, 519, A20

Barklem, P. S., Belyaev, A. K., Guitou, M., et al. 2011, A\& $A$, 530, A94

Barragán, P., Errea, L. F., Guzmán, F., et al. 2010, PhRvA, 81, 062712

Bartecka, A., Baclawski, A., \& Musielok, J. 2011, Cent. Eur. J. Phys., 9, 131

Bautista, M. A., Quinet, P., Palmeri, P., et al. 2009, A\&A, 508, 1527

Bellm, S., Lower, J., Weigold, E., \& Mueller, D. W. 2010, PRL, 104, 023202

Ben Nessib, N. 2009, New Astron. Rev., 53, 255

Bernotas, A., Karazija, R., \& Rudzikas, Z., eds. 2011, Proc. $7^{\text {th }}$ International Conference on Atomic and Molecular Data and their Applications, AIP-CP, 1344

Blanquet, G., Auwera, J. V., \& Lepère, M. 2009, JMoSp, 255, 72

Bouchiha, D., Caron, L. G., Gorfinkiel, J. D., \& Sanche, L. 2008, JPhB: At. Mol. Opt. Phys., 41, 045204

Boussetta, Z., Aroui, H., Jacquemart, D., et al. 2011, JQSRT, 112, 769

Bray, I., Fursa, D. V., Kadyrov, A. S., \& Stelbovics, A. T. 2010, PhRvA, 81, 062704

Bukvić, S., Žigman, V., Srećković, A. \& Djeniže, S. 2008, JQSRT, 109, 2869

Bukvić, S., Djeniže, S., \& Srećković, A. 2009a, A\&AA, 508, 491

Bukvić, S., Djeniže, S., Srećković, A., \& Nikolić, Z. 2009b, Phys. Lett. A, 373, 2750

Bukvić, S., Djeniže, S., Nikolić, Z., \& Srećković, A. 2011, A\&A, 529, A83

Butler, K. \& Badnell, N. R. 2008, A\&A A, 489, 1369

Cabrera-Trujillo, R., Sabin, J. R., Deumens, E., \& Öhrn, Y. 2008, PhRvA, 78, 012707

Cabrera-Trujillo, R., Amaya-Tapia, A., \& Antillón, A. 2009, PhRvA, 79, 012712

Cabrera-Trujillo, R., Sabin, J. R., Öhrn, Y., et al. 2011, PhRvA, 83, 012715

Calisti, A., Mossé, C., Ferri, S., et al. 2010, PhRvE, 81, 016406

Cazzoli, G., Puzzarini, C., Buffa, G., \& Tarrini, O. 2008, JQSRT, 109, 2820

Cazzoli, G., Puzzarini, C., Buffa, G., \& Tarrini, O. 2009, JQSRT, 110, 609

Celiberto, R., Janev, R. K., Wadehra, J. M., \& Laricchiuta, A. 2009, PhRvA, 80, 012712

Celiberto, R., Janev, R. K., Wadehra, J. M., \& Laricchiuta, A. 2011, PhRvA, 84, 012707

Chluba, J., Vasil, G. M., \& Dursi, L. J. 2010, MNRAS, 407, 599

Chourou, S. T. \& Orel, A. E. 2008, PhRvA, 77, 042709

Christova, M., Dimitrijević, M. S., \& Kovačević, A. 2010a, JP-CS, 207, 2024

Christova, M., Dimitrijević, M. S., Simić, S., \& Sahal-Bréchot, S. 2010b, JP-CS, 207, 2025

Ćirišan, M., Peláez, R. J., Djurović, S., et al. 2011, PhRvA, 83, 012513

da Costa, R. F., Bettega, M. H. F., \& Lima, M. A. P. 2008, PhRvA, 77, 042723

Del Zanna, G., Rozum, I. \& Badnell, N. R. 2008 A\&A, 487, 1203

Del Zanna, G., Storey, P. J. \& Mason, H. E. 2010 A\&A, 514, A40

Deng, W., Mondelain, D., Thibault, F., et al. 2009, JMoSp, 256, 102

Dere, K. P., Landi, E., Young, P. R., et al. 2009, A $\& A$, 498, 915 
Devi, V. M., Benner, D. C., Miller, C. E., \& Predoi-Cross, A. 2010a, JQSRT, 111, 2355

Devi, V. M., Benner, D. C., Rinsland, C. P., et al. 2010b, JQSRT, 111, 2481

Devi, V. M., Rinsland, C. P., Benner, D. C., et al. 2010c, JQSRT, 111, 1234

Dhib, M. 2010, JMoSp, 259, 80

Dhyne, M., Fissiaux, L., Populaire, J.-C., \& Lepère, M. 2009, JQSRT, 110, 358

Dhyne, M., Joubert, P., Populaire, J.-C., \& Lepère, M. 2010, JQSRT, 111, 973

Dhyne, M., Joubert, P., Populaire, J.-C., \& Lepère, M. 2011, JQSRT, 112, 969

Dick, M. J., Drouin, B. J., Crawford, T. J., \& Pearson, J. C. 2009a, JQSRT, 110, 628

Dick, M. J., Drouin, B. J., \& Pearson, J. C. 2009b, JQSRT, 110, 619

Dick, M. J., Drouin, B. J., \& Pearson, J. C. 2010, PhRvA, 81, 022706

Ding, B. W., Chen, X. M., Yu, D. Y., et al. 2008, PhRvA, 78, 062718

Djeniže, S. 2008, Phys. Lett. A, 372, 6658

Djeniže, S. 2009, Spectrochim. Acta B, 64, 242

Djeniže, S., Srećković, A., \& Bukvić, S. 2009, EuPhJD, 62, 185

Djurović, S., Ćirišan, M., Demura, A. V., et al. 2009, PhRvE, 79, 046402

Djurović, S., Mar, S., Peláez, R. J., \& Aparicio, J. A. 2011, MNRAS, 414, 1389

Domanskaya, A. V., Bulanin, M. O., Kerl, K., \& Maul, C. 2009, JMoSp, 253, 20

Domanskaya, A. V., Asfin, R. E., Maul, C., et al. 2011, JMoSp, 265, 69

Drouin, B. J. \& Gamache, R. R. 2008, JMoSp, 251, 194

Dubernet, M. L., Boudon, V., Culhane, J. L., et al. 2011, JQSRT, 111, 2151

Elabidi, H. \& Sahal-Bréchot, S. 2011, EuPhJD, 61, 285

Elabidi, H., Sahal-Bréchot, S., \& Ben Nessib, N. 2009, EuPhJD, 54, 51

Elabidi, H., Sahal-Bréchot, S., Dimitrijević, M. S., \& Ben Nessib, N. 2011, MNRAS, 417, 2624

Fang, X., Storey, P. J. \& Liu, X.-W. 2011 A $\& A$, 530, A18

Farooq, A., Jeffries, J. B., \& Hanson, R. K. 2010, JQSRT, 111, 949

Fedor, J., May, O., \& Allan, M. 2008, PhRvA, 78, 032701

Fedor, J., Winstead, C., McKoy, V., et al. 2010, PhRvA, 81, 042702

Felfi, Z., Msezane, A. Z., \& Sokolovski, D. 2011, PhRvA, 83, 052705

Fiadzomor, P. A. Y., Keen, A. M., Grant, R. B., \& Orr-Ewing, A. J. 2008, Chem. Phys. Lett., 462,188

Fifirig, M. \& Stroe, M. 2008, Phys. Scr., 78, 065302

Fischer, D., Gudmundsson, M., Berényi, Z., et al. 2010, PhRvA, 81, 012714

Fissiaux, L., Dhyne, M., \& Lepère, M. 2009, JMoSp, 254, 10

Fissiaux, L., Blanquet, G., \& Lepère, M. 2010, JQSRT, 111, 2037

Flaud, J.-M., Lafferty, W. J., Devi, V. M., et al. 2011, JMoSp, 267, 3

Gabard, T. \& Boudon, V. 2010, JQSRT, 111, 1328

Galalou, S., Ben Mabrouk, K., Aroui, H., et al. 2011, JQSRT, 112, 2750

Gamache, R. R. \& Laraia, A. L. 2009 JMoSp, 257, 116

Gamache, R. R., Laraia, A. L. \& Lamouroux, J. 2011 Icarus, 213, 720

Gangwar, R. K., Tripathi, A. N., Sharma, L., \& Srivastava, R. 2010, JPhB: At. Mol. Opt. Phys., 43,085205

Gao, H. M., Ma, S. I., Xu, C. M., \& Vu, L. 2008, EuPhJD, 47, 191

Garcia, P. M. Y., Sigaud, G. M., Luna, H., et al. 2008, PhRvA, 77, 052708

Gargioni, E. \& Grosswendt, B. 2008, Rev. Mod. Phys., 80, 451

Getahun, H., Errea, L. F., Illescas, C., et al. 2010, EuPhJD, 60, 45

Gigosos, M. A. \& González, M. Á. (eds.) 2008, Proc. 19th International Conference on Spectral Line Shapes, AIP-CP, 1058

Gigosos, M. A. \& González, M. Á. 2009, A\&A, 503, 293

Glosík, I., Plašil, R., Korolov, I., et al. 2009, PhRvA, 79, 052707

Gochitashvili, M. R., Kezerashvili, R. Ya., \& Lomsadze, R. A. 2010, PhRvA, 82, 022702

Goméz, L., Jacquemart, D., Bouanich, J.-P., et al. 2010, JQSRT, 111, 1252

Goméz, L., Ivanov, S. V., Buzykin, O. G., \& Thibault, F. 2011, JQSRT, 112, 1942

González-Magaña, O., Cabrera-Trujillo, R. \& Hinojosa, G. 2008, PhRvA, 78, 052712

González, M. Á., Ivković, M., Gigosos, M. A., et al. 2011, A\&̛A, 503, 293 
Gordon, M. A. \& Sorochenko, R. L. 2009, Radio Recombination Lines (New York:Springer Science+Business Media)

Guevara, N. L., Teixeira, E., Hall, B., et al. 2011, PhRvA, 83, 052709

Guinet, M., Jeseck, P., Mondelain, D., et al. 2011, JQSRT, 112, 1950

Gulidova, O. S., Asfin, R. E., Grigoriev, I. M., \& Filippov, N. N. 2010, JQSRT, 111, 2315

Guzmán, F., Errea, L. F., \& Pons, B. 2009, PhRvA, 80, 042708

Halmová, G., Gorfinkiel, J. D., \& Tennyson, J. 2008, JPhB: At. Mol. Opt. Phys., 41, 155201

Hamberg, M., Österdahl, F., Thomas, R. D., et al. 2010a, A\&\&A, 514, A83

Hamberg, M., Zhaunerchyk, V., Vigren, E., et al. 2010b, A\&\&A, 522, A90

Hanley, T. R., Steffes, P. G., \& Karpowicz, B. M. 2009, Icarus, 202, 316

Harris, A. L., Peacher, J. L., Schulz, M., \& Madison, D. H. 2010, JP-CS, 212, 012031

Harrison, S. \& Tennyson, J. 2011, JPhB: At. Mol. Opt. Phys., 44, 045206

Hartmann, J.-M. 2009, JQSRT, 110, 2019

Hartmann, J.-M., Boulet, C., \& Robert, D. 2008, Collisional Effects on Molecular Spectra (Amsterdam:Elsevier)

Hoffman, K. J. \& Davies, P. B. 2009, JMoSp, 254, 69

Holtkötter, I. \& Hanne, G. F. 2009, PhRvA, 80, 022709

Hudson, C. E., Ramsbottom, C. A., Norrington, P. H. \& Scott, M. P. 2009, A\&BA, 494, 729

Hurtmans, D., Henry, A., Valentin, A., \& Boulet, C. 2009, JMoSp, 254, 126

Hwang, S. M., Kojima, J. N., Nguyen, Q.-V., \& Rabinowitz, M. J. 2008, JQSRT, 109, 2715

Illescas, C., Errea, L. F., \& Méndez, L., et al. 2011, PhRvA, 83, 052704

Ivanov, S. V. \& Buzykin, O. G. 2010, JQSRT, 111, 2341

Ivković, M., González, M. Á., \& Jovićević, S., et al. 2010, Publ. Astron. Obs. Belgrade, 89, 201

Jacquemart, D., Laraia, A. L., \& Tchana, F. K., et al. 2010, JQSRT, 111, 1209

Jacquinet-Husson, N., Scott, N. A., \& Chedin, A., et al. 2008, JQSRT, 109, 1043

Jalbert, G., Wolff, W., Magalhães, S. D., \& de Castro Faria, N. V. 2008, PhRvA, 77, 012722

Jiao, L., Zhou, Y., \& Wang, Y. 2010, PhRvA, 81, 042713

Johnson P. V., Young, J. A. \& Malone, C. P., et al. 2010, JP-CS, 204, 012003

Joshipura, K. N. \& Gangopadhyay, S. 2008, JPhB: At. Mol. Opt. Phys., 41, 215205

Kamber, E. Y., Abu-Haija, O., \& Wardwell, J. A. 2008, PhRvA, 77, 012701

Kato, H., Suzuki, D., \& Ohkawa, M., et al. 2010, PhRvA, 81, 042717

Kaur, S. \& Baluja, K. L. 2010, PhRvA, 82, 022717

Kaur, S., Bharadvaja, A., \& Baluja, K. L. 2011, PhRvA, 83, 062707

Keenan, F. P. Crockett, P. J., \& Aggarwal, K. M., et al. 2009, A\& A, 495, 359

Khoma, M. V., Lazur, V. Yu., \& Janev, R. K. 2009, PhRvA, 80, 032706

Koshelev M. A. \& Tretyakov, M. Yu. 2009, JQSRT, 110, 118

Koshelev M. A. \& Markov, V. N. 2009, JQSRT, 110, 526

Koshelev M. A. 2011, JQSRT 112, 550

Kothari, H. N., Pandya, S. H., \& Joshipura, K. N. 2011, JPhB: At. Mol. Opt. Phys., 44, 125202

Koubek, J. \& Boulet, C., Perrin A., et al. 2011, JMoSp, 266, 12

Kretinin, I. Yu, Krisilov, A. V. \& Zon, B. A. 2008 JPhB: At. Mol. Opt. Phys., 41, 215206

Krupnov, A. F. 2010, PhRvA, 82, 036703

Kumari, S., Chatterjee, S. N., Jha, L. K., \& Roy, B. N. 2011, EuPhJD, 61, 355

Kupka, F., Piskunov, N., \& Ryabchikova, T. A., et al. 1999, A\&AS, 138, 119

Kurucz, R. L. 2011, CanJPhys, 89, 417

Lamouroux, J., Tran, H., \& Laraia, A. L., et al. 2010, JQSRT, 111, 2321

Laraia, A. L., Gamache, R. R., \& Hartmann, J.-M., et al. 2009, JQSRT, 110, 687

Lavrentieva, N. N., Petrova, T. M., Solodov, A. M., \& Solodov, A. A. 2010, JQSRT, 111, 2291

Lewis, J. K. C. \& Predoi-Cross, A. (eds.) 2010, Proc. 20th International Conference on Spectral Line Shapes, AIP-CP, 1290

Li, J. S., Liu, K., \& Zhang, W. J., et al. 2008, JMoSp, 252, 9

Li, J. S., Durry, G., \& Cousin, J., et al. 2010, JQSRT, 111, 2332

Liang, G. Y., Whiteford, A. D., \& Badnell, N. R. 2009a, A\&A, 499, 943

Liang, G. Y., Whiteford, A. D., \& Badnell, N. R. 2009b, A\&A, 500, 1263 
Liang, G. Y. \& Badnell, N. R. 2010, A\&A, 518, A64

Liang, G. Y. \& Badnell, N. R. 2011, A\&̈A, 528, A69

Liang, G. Y., Badnell, N. R., \& Zhao, G., et al. 2011, A\&A, 533, A87

Lin, Y. \& Mayer, P. M. 2010, Chem. Phys., 378, 103

Lisak, D., Havey, D. K., \& Hodges, J. T. 2009, PhRvA, 79, 052507

Lisak, D., Masłowski, P., \& Cygan, A., et al. 2010, PhRvA, 81, 042504

Liu, J.-B. \& Zhou, Ya.-J. 2010, Chin. Phys. B, 19, 093403

Liu, L., Liu, C. H., Wang, J. G., \& Janev, R. K. 2011, PhRvA, 84, 032710

Liu, X. J., Wang, J. G., Qu, Y. Z., \& Buenker, R. J. 2011, PhRvA, 84, 042706

Long, D. A., Havey, D. K., \& Okumura, M., et al. 2010, JQSRT, 111, 2021

Long, D. A., Havey, D. K., \& Yu, S. S., et al. 2011, JQSRT, 112, 2527

Ludlow, J. A., Lee, T. G., \& Ballance, C. P., et al. 2011, PhRvA, 84, 022701

Lyulin, O. M., Nikitin, A. V., \& Perevalov, V. I., et al. 2009, JQSRT, 110, 654

Lyulin, O. M., Perevalov, V. I., \& Morino, I., et al. 2011, JQSRT, 112, 531

Machado, L. E., Sugohara, R. T., \& dos Santos, A. S., et al. 2011, PhRvA, 84, 032709

McRaven, C. P., Cich, M. J., \& Lopez, G. V., et al. 2011, JMoSp, 266, 43

Malespin, C., Ballance, C. P., \& Pindzola, M. S., et al. 2011, A\&AA, 526, A115

Mančev, I. 2009, EuPhJD, 51, 213

Martin, B. \& Lepère, M. 2009, JMoSp, 255, 6

Mashonkina, L. 2009, Phys. Scr., T134, 014004

Mavadat, M., Ricard, A., Sarra-Bournet, C., \& Laroche, G. 2011, JPhD: Appl. Phys., 44, 155207

Mijatović, Z., Nikolić, D., Kobilarov, R. \& Ivković, M. 2010a, Publ. Astron. Obs. Belgrade, 89, 217

Mijatović, Z., Nikolić, D., Kobilarov, R. \& Ivković, M. 2010b, JQSRT, 111, 990

Miraglia, J. E. \& Gravielle, M. S. 2008, PhRvA, 78, 052705

Misago, F., Lepèere, M., Bouanich, J.-P., \& Blanquet, G. 2009, JMoSp, 254, 16

Mitroy, J. \& Zhang, J. Y. 2008, EuPhJD, 46, 415

Miyano, S. \& Tonokura, K. 2011, JMoSp, 265, 47

Monce, M. N., Pan, S., Radeva, N. L., \& Pepper, J. L. 2009, PhRvA, 79, 012704

Müller, H. S. P., Schlöder, F., Stutzki, J., \& Winnewisser, G. 2005, JMoStr, 742, 215

Munjal, H., Baluja, K. L., \& Tennyson, J. 2009, PhRvA, 79, 032712

Nagao, M., Hida, K., \& Kimura, M., et al. 2008, PhRvA, 78, 012708

Nguyen, L., Blanquet, G., Dhyne, M., \& Lepèere, M. 2009a, JMoSp, 254, 94

Nguyen, L., Blanquet, G., Populaire, J.-C., \& Lepèere, M. 2009b, JQSRT, 110, 367

Nikolić, D., Gorczyca, T. W., Korista, K. T., \& Badnell, N. R. 2010, A\&\&A, 516, A97

Nouri, S., Ben Mabrouk, K., \& Chelin, P., et al. 2008, JMoSp, 258, 75

Ogurtsov, G. N., Ovchinnikov, S. Yu., Macek, J. H. \& Mikoushkin, V. M. 2011, PhRvA, 84, 032706

Omar, B. 2010, Int. J. Spectrosc., 506346

Omar, B. 2011, J. At. Mol. Opt. Phys, ID 850807

Orel, A. E., Starace, A. F., \& Nikolić, D., et al. (eds.) 2009, Proc. XXVI International Conference on Photonic, Electronic 83 Atomic Collisions, JP-CS, 194

Palmeri, P., Quinet, P., \& Mendoza, C., et al. 2011, A\&A, 525, A59

Peach, G., Dimitrijević, M. S., \& Stancil, P. C. 2009, in Karel A. van der Hucht (ed.), Reports on Astronomy 2006-2009, IAU Transactions XXVIIA (Cambridge: CUP), 385

Peach, G. \& Whittingham, I. B. 2009, New Astron. Rev., 53, 227

Peach, G. 2010a, in: Mem. S.A.It. Suppl., 15, 68

Peach, G. 2010b, in: Spectral Line Shapes, Proc. 20th Intern. Conf., AIP-CP, 1290, 14

Peláez, R. J., Djurović, S., \& Ćirišan, M., et al. 2009a, JPhB: At. Mol. Opt. Phys., 42, 125002

Peláez, R. J., Djurović, S., \& Ćirišan, M., et al. 2009b, A\&A, 507, 1697

Peláez, R. J., Djurović, S., \& Ćirišan, M., et al. 2010a, A $\& A$, 518, A60

Peláez, R. J., Djurović, S., Ćirišan, M., Aparicio, J. A., \& Mar, S. 2010b, JP-CS, 257, 2021

Petrova, T. M., Solodov, A. M., \& Solodov, A. A., et al. 2011, JQSRT, 112, 2741

Phelps, A. V. 2009, PhRvE, 79, 066401 
Phillips, G. T. \& Perram, G. P. 2008, JQSRT, 109, 1875

Phillips, K. J. H., Aggarwal, K. M., Landi, E., \& Keenan, F. P. 2010, A\&6A, 518, A41

Pitz, G. A., Fox, C. D., \& Perram, G. P. 2010, PhRvA, 82, 042502

Popović, L. Č. \& Dimitrijević, M. S. (eds.) 2009, Proc. 7th Serbian Conf. Spectral Line Shapes in Astrophysics, New Astron. Rev., 53, 107

Povey, C., Predoi-Cross, A., \& Hurtmans, D. R. 2011, JMoSp, 268, 177

Predoi-Cross, A., Liu, W., \& Murphy, R., et al. 2010, JQSRT, 111, 1065

Ptashnik, I. V. \& Smith, K. M. 2010, JQSRT, 111, 1317

Rajvanshi, J. S. \& Baluja, K. L. 2010, PhRvA, 82, 062710

Rajvanshi, J. S. \& Baluja, K. L. 2011, PhRvA, 84, 042711

Reggami, L., Bouledroua, M., Allouche, A. R., \& Aubert-Frécon, M. 2009, JQSRT, 110, 72

Ren, X., Bray, I., \& Fursa, D. V., et al. 2011, PhRvA, 83, 052711

Rixon, G., Dubernet, M. L., \& Piskunov, N., et al. 2011, AIP-CP, 1344, 107

Roos, J. B., Larson, A. A., \& Orel, A. E. 2008, $P h R v A, 78,022508$

Roos, J. B., Orel, A. E., \& Larson, Å. A. 2009, PhRvA, 79, 062510

Rosato, J., Marandet, Y., \& Capes, H., et al. 2009, PhRvE, 79, 046408

Rosato, J., Boland, D., \& Difallah, M., et al. 2010, Int. J. Spectrosc., 374372

Rosenberry, M. A. \& Stewart B. 2011, JPhB: At. Mol. Opt. Phys., 44, 055207

Rothman, L. S., Gordon, I. E., \& Barbe, A., et al. 2009, JQSRT, 110, 533

Rothman, L. S., Gordon, I. E., \& Barbe, A., et al. 2010, JQSRT, 111, 2139

Rozsályi, E., Bene, E., \& Halász, G. J., et al. 2011, PhRvA, 83, 052713

Sabido, M, de Andrés, J. \& Sogas, J., et al. 2008, EuPhJD, 47, 63

Sagawa, H., Mendrok, J., \& Seta, T., et al. 2009, JQSRT, 110, 2027

Sahal-Bréchot, S. 2010, JP-CS, 257, 2037

Samanta, R. \& Purkait, M. 2011, EuPhJD, 64, 311

Samanta, R., Purkait, M., \& Mandal, C. R. 2011, PhRvA, 83, 032706

Santos, A. C. F., Sigaud, G. M., \& Melo, W. S., et al. 2010, PhRvA, 82, 012704

Sato, T. O., Mizoguchi, A., \& Mendrok, J., et al. 2010, JQSRT, 111, 821

Schmidt, E. W., Schippers, S., \& Bernhardt, D., et al. 2008, A\&A, 492, 265

Schöfller, M. S., Titze, J., \& Schmidt, Ph. H., et al. 2009, PhRvA, 79, 064701

Shafir, D., Novotny, S., \& Buhr, H., et al. 2009, PRL, 102, 223202

Smith, M. A. H., Benner, D. C., Predoi-Cross, A., \& Devi, V. M. 2009, JQSRT, 110, 639

Smith, M. A. H., Benner, D. C., Predoi-Cross, A., \& Devi, V. M. 2010, JQSRT, 111, 1152

Smith, M. A. H., Benner, D. C., Predoi-Cross, A., \& Devi, V. M. 2011, JQSRT, 112, 952

Stäuber, P. \& Bruderer, S. 2009, A\& A, 505, 195

Stéhle, C. \& Fouquet, S. 2010, Int. J. Spectrosc., 506346

Stenrup, M., Larson, Å. A., \& Elander, N. 2009, PhRvA, 79, 012713

Sterling, N. C. \& Witthoeft, M. C. 2011, A\&A, 529, A147

Stolterfoht, N., Cabrera-Trujillo, R., \& Krstić, P. S., et al. 2010, PhRvA, 81, 052704

Storey, P. J. \& Zeippen, C. J. 2010, A\&A, 511, A78

Stroe, M. \& Fifirig, M. 2011, EuPhJD, 61, 63

Szmytkowski, C., Domaracka, A. Możejko, P., \& Ptasińska-Denga, E. 2008, JPhB: At. Mol. Opt. Phys., 41, 065204

Takagi, H., Hara, S., \& Sato, H. 2009, PhRvA, 79, 012715

Talbi, F., Bouledroua, M., \& Alioua, K. 2008, EuPhJD, 50, 141

Tapalaga, I., Dojčinović, I. P., \& Purić, J. 2011, MNRAS, 415, 503

Tarana, M. \& Tennyson, J. 2008, JPhB: At. Mol. Opt. Phys., 41, 205204

Tayal, S. S. \& Zatsarinny, O. 2010, A\&A A, 510, A79

Thibault, F., Fuller, E. P., \& Grabow, K. A., et al. 2009, JMoSp, 256, 17

Thibault, F., Ivanov, S. V., \& Buzykin, O. G., et al. 2011a, JQSRT, 112, 1429

Thibault, F., Martinez, R. Z., Bermejo, D., \& Goméz, L. 2011b, JQSRT, 112, 2542

Tran, H., Boulet, C., \& Stefani, S., et al. 2011a, JQSRT, 112, 925

Tran, H., Thibault, F., \& Hartmann, J.-M. 2011b, JQSRT, 112, 1035

Tran, H., Picquet-Varrault, B., \& Boursier, C., et al. 2011c, JQSRT, 112, 2287 
Tremblay, P.-E. \& Bergeron, P. 2009, ApJ, 696, 1755

Vadla, C., Horvatic, V., \& Niemax, K. 2009, PhRvA, 80, 052506

Vangvichith, M., Tran, H., \& Hartmann, J.-M. 2009, JQSRT, 110, 2212

Vinodkumar, M., Limbachiya, C., \& Joshipura, K. N., et al. 2008, JP-CS, 115, 012013

Voronin, B. A., Lavrentieva, N. N., \& Mishina, T. P., et al. 2010, JQSRT, 111, 2308

Wang, Y. C., Zhou, Y., Cheng, Y., \& Ma, J. 2009, Chin. Phys. Lett., 26, 083401

Wang, Y. C., Zhou, Y., \& Cheng, Y., et al. 2010, JPhB: At. Mol. Opt. Phys., 43, 045201

Wiesenfeld, L. \& Faure, A. 2010, PhRvA, 82, 040702(R)

Winter, T. G. 2009, PhRvA, 80, 032701

Wójtewicz, S., Lisak, D., \& Cygan, A., et al. 2011, PhRvA, 84, 032511

Wu, Y., Qi, Y. Y., \& Zou, S. Y., et al. 2009, PhRvA, 79, 062711

Wu, Y., Qi, Y. Y., \& Yan, J., et al. 2009, PhRvA, 80, 022715

Yang, C., Buldyreva, J., Gordon, I. E., et al. 2008 JQSRT, 109, 2857

Zameroski, N. D., Hager, G. D., \& Rudolph, W., et al. 2011, JQSRT, 112, 59

Zapukhlyak, M. \& Kirchner, T. 2009, PhRvA, 80, 062705

Zatsarinny, O., Bartschat, K., \& Gedeon, S., et al. 2009, PhRvA, 79, 052709

Zatsarinny, O., Bartschat, K., \& Garcia, G., et al. 2011, PhRvA, 83, 042702

Zhang, S. B., Wang, J. G., \& Janev, R. K. 2010, PhRvA, 81, 032707

Zhang, S. B., Wang, J. G., Janev, R. K., \& Chen, X. J. 2011, PhRvA, 83, 032724

Zielinska, S., Pellerin, S., \& Dzierzega, K., et al. 2010, JPhD: Appl. Phys., 43, 434005

Zmerli, B., Ben Nessib, N., Dimitrijević, M. S., \& Sahal-Bréchot, S. 2010, Phys. Scr., 82, 055301 